\title{
Cumulative financial stress as a potential risk factor for cancer-related fatigue among prostate cancer survivors
}

\author{
Liya Lu ${ }^{1}$ (D) $\cdot$ Anna Gavin $^{2} \cdot$ Frances J. Drummond ${ }^{3} \cdot$ Linda Sharp $^{1}$
}

Received: 3 April 2020 / Accepted: 14 June 2020 / Published online: 1 August 2020

(C) The Author(s) 2020

\begin{abstract}
Introduction Cancer-related fatigue (CRF) is the most commonly reported treatment-related side effect of prostate cancer (PCa). Recognition of financial hardship among cancer survivors is growing. We investigated, for the first time, associations between levels of financial stress and CRF among PCa survivors.

Methods We used data from PCa survivors who had been identified through two population-based cancer registries covering the Republic of Ireland and Northern Ireland and had completed a postal questionnaire. CRF was measured by the fatigue subscale of the EORTC QLQ-C30. Financial stress was assessed as household ability to make ends meet (i) pre-diagnosis and (ii) at questionnaire completion (post-diagnosis). Multivariable logistic regression was used to relate financial stress to clinically important CRF (fatigue subscale score $\geq 39$ of a possible 100).

Results Two thousand four hundred fifty-eight PCa survivors were included. Of these, 268 (10.9\%) reported pre-diagnosis financial stress only, 317 (12.9\%) post-diagnosis stress only and $270(11.0 \%)$ both pre- and post-diagnosis stress (cumulative stress); 470 (19.1\%) reported clinically important CRF. After controlling for confounders, survivors with cumulative financial stress exposure were significantly more likely to have CRF (OR $=4.58,95 \%$ CI 3.30-6.35, $p<0.001)$, compared with those without financial stress. There was a suggestion of a dose-response relationship ( $\mathrm{OR}=1.83,95 \% \mathrm{CI} 1.27-2.65, p=0.001$ for prediagnosis financial stress only; and $\mathrm{OR}=4.11,95 \%$ CI 3.01-5.61, $p<0.001$ for post-diagnosis financial stress only).

Conclusions Financial stress may be an independent risk factor for CRF.

Implications for Cancer Survivors There may be benefits in targeting interventions for reducing CRF towards survivors with financial stress, or developing strategies to reduce financial stress.
\end{abstract}

Keywords Prostate cancer $\cdot$ Financial stress $\cdot$ Cancer-related fatigue $\cdot$ Ireland

\section{Introduction}

An estimated 1.3 million new prostate cancers (PCas) are diagnosed worldwide each year, and it is the most common cancer among men in the WHO regions of Europe, the Americas and Africa [1]. Prevalence is increasing due to early

Electronic supplementary material The online version of this article (https://doi.org/10.1007/s11764-020-00906-7) contains supplementary material, which is available to authorized users.

Liya Lu

liya.lu@newcastle.ac.uk

1 Population Health Sciences Institute, Newcastle University Centre for Cancer, Newcastle University, Newcastle, England

2 Northern Ireland Cancer Registry, Queen's College Belfast, Belfast, Northern Ireland

3 CancerResearch@UCC, University College Cork, Cork, Ireland detection and 5-year survival now exceeds 90\% in many populations, including Canada, Brazil, Australia, Japan and much of Northern and Western Europe [2]. Consequently, in many countries, more men are living with $\mathrm{PCa}$ than any other form of cancer: for example, there are more than 6 million $\mathrm{PCa}$ survivors in the USA [3], 250,000 in the UK [4] and 24,000 in the Republic of Ireland (RoI) [5]. These numbers are projected to rise rapidly [6]. Understanding the needs and outcomes of this growing population is therefore important.

Cancer-related fatigue (CRF) is a prolonged, distressing and subjective sense of physical, emotional or cognitive exhaustion associated with cancer or its treatment [7]. It can result from current mainstream treatments for $\mathrm{PCa}$, particularly androgen deprivation therapy (ADT) [8]. Indeed, it is the most commonly reported treatment-related side effect of $\mathrm{PCa}$ $[9,10]$. In our own work, we found that PCa survivors had worse scores for fatigue than any other general cancer-related symptoms recorded on the EORTC QLQ-C30 [11]. Others have reported that CRF may be found in up to three-quarters 
of men with PCa [8]. Clinically significant levels of fatigue among PCa survivors have been associated with severe psychological distress [12].

CRF interferes with functional capacity and is not proportional to recent activity nor relieved by rest or sleep [7]. It can impact on survivors' lives for years after treatment cessation [13]. Despite this, relatively little research has investigated correlates of CRF among survivors. Most studies have been conducted in breast cancer survivors [14-17] or survivors of common cancer types combined [18]. These suggest that, among other factors, economic variables, such as lower household income, may be associated with higher risk of CRF [14].

Recognition of financial hardship among cancer survivors is growing [19-23]. Survivors may be vulnerable to material financial hardship (henceforth financial stress) [24] due to outof-pocket costs as a result of the cancer diagnosis (e.g. for medical care, supportive medications, travel to appointments) and lost income because of work absence during cancer treatment and rehabilitation [19]. Such financial stress appears particularly common in survivors with low income or financial stress before diagnosis [25-28] and has been associated with poor psychological well-being and worse quality of life (QoL) in a range of cancers [23, 26, 29-31]. These findings have led to a recent call to increase knowledge of the relationship between financial stress and cancer-related symptoms or side effects, particularly those with physical manifestations [32]; better understanding of this could inform development and targeting of interventions among survivors.

The aim of this study, therefore, was to investigate - for the first time - the association between levels of financial stress (pre-diagnosis, post-diagnosis and cumulative) and CRF among PCa survivors.

\section{Patients and methods}

\section{Design and setting}

The Prostate Cancer Treatment-your experience (PiCTure) study was a cross-sectional study of PCa survivors sampled and recruited via two population-based cancer registries on the island of Ireland: the National Cancer Registry Ireland (NCRI) in the Republic of Ireland (RoI) and the Northern Ireland (NI) Cancer Registry (NICR). The RoI has a mixed public-private healthcare system where individuals who use the public system make modest co-payments for public health services and full payments for prescribed medications unless they have a medical card (entitlement to which is based on means and age). Private health insurance plans generally cover hospital care. NI, part of UK, has a primarily public healthcare system, the National Health Service. The PiCTure study was approved by the College of General Practitioners in the RoI and the Office for Research Ethics Committee in NI [33].

\section{Identification and recruitment of survivors}

All men diagnosed with incident primary invasive $\mathrm{PCa}$ (ICD10 C61) between 01/01/1995 and 31/03/2010 and alive 31/03/2011 were identified from NCRI and NICR (RoI = 17,304; NI =5519). As previously described [11], a country and time since diagnosis-stratified random sample of 12,322 survivors (54\% of sampling frame comprising approximately equal numbers $<5$ and $\geq 5$ years post-diagnosis in each jurisdiction) was screened for eligibility by healthcare providers. Eligible survivors had to be alive and aware of $\mathrm{PCa}$ diagnosis, living in RoI/NI, English-speaking, and potentially able to complete a questionnaire.

\section{Data collection and measures}

Following health professional screening, a postal survey was sent to 6659 eligible survivors. Non-respondents were sent up to two written reminders at fortnightly intervals. Questionnaire responses were linked to the cancer registry records to obtain date of birth, date of diagnosis (and hence time since diagnosis), clinical stage and Gleason grade. Full details of the questionnaire content are provided elsewhere [33]. It collected demographic (e.g. marital status, education, employment status) and clinical data (e.g. presence of comorbidities at diagnosis of cancer, treatment received following diagnosis). CRF in the week prior to the questionnaire completion was assessed using the fatigue scale (FA) of the European Organization for Research and Treatment of Cancer Quality of Life Core Questionnaire (EORTC QLQ$\mathrm{C} 30$ ), a validated instrument for capturing health-related quality of life (HRQoL) in cancer patients/survivors [34, 35]. A FA subscale score $\geq 39$ out of a possible 100 indicates the presence of clinically important CRF [36]. To assess prediagnosis financial stress, participants were asked to report the level of financial stress they had experienced just before their cancer diagnosis. The question was derived from previous research and asked about the ability of the survivor's household to make ends meet immediately before diagnosis $[28,37]$. Responses were on a 6-level Likert type scale ranging from "Very difficult" to "Very easy". Participants were considered to have pre-diagnosis financial stress if they responded "Very difficult/Difficult/Somewhat difficult". To assess post-diagnosis financial stress, participants were asked about the period of time since the cancer diagnosis; the question asked about the impact of the cancer on the ability of the survivor's household to make ends meet. Responses were on a 7-level Likert type scale (including a central "no change" option). Participants were considered to have post-diagnosis financial stress if they responded "Much more difficult/More 
difficult/A little more difficult". We applied a cumulative perspective to investigate whether survivors with higher levels of financial stress exposure were more fatigued. On this basis, cumulative financial stress exposure was defined as exposure to both pre-diagnosis and post-diagnosis financial stress.

For analysis, the study population was categorised as follows: $\leq 59,60-69, \geq 70$ years of age at diagnosis; married/living with a partner and other; living alone at diagnosis or not; primary, secondary or $\geq$ tertiary as highest level of education at diagnosis; working (employed/self-employed), not working (retired, unemployed, unable to work due to disability/sickness) and other employment status; any or no comorbidities at diagnosis; early (localised disease: stage I/II and Gleason score 2-7 at diagnosis), late (locally advanced/advanced disease: III/IV and any Gleason score at diagnosis) unknown extent (other combinations of stage and Gleason score, or unknown stage or Gleason score) of disease; and time since diagnosis $(2-5,5-10, \geq 10$ years. A mutually exclusive hierarchical treatment variable was created based on primary treatment(s) ever received, as follows: radical prostatectomy (RP) with or without other treatments; external beam radiotherapy (EBRT) with or without concurrent ADT; brachytherapy (BT) without EBRT or RP; ADT alone without RP, EBRT or BT; active surveillance/watchful-waiting; and other.

\section{Statistical analyses}

The study population comprised questionnaire respondents who had completed the CRF questions and the questions on financial stress. We used $\chi^{2}$ tests to compare the sociodemographic and clinical characteristics of this group with those respondents who did not complete these questions. The frequencies and percentages of explanatory variables were summarised for the entire study population. We summarised the frequencies of pre-diagnosis, post-diagnosis and cumulative financial stress across the study population and by key socio-demographic and clinical variables. We then used $\chi^{2}$ tests to compare subgroups of participants by presence and absence of CRF. Tests for trend were conducted across categories of financial stress and for other variables which were ordinal. Multivariable logistic regression analyses were performed to examine the association between financial stress exposure and CRF, adjusting for covariates. The model fitting involved the following steps: (i) all variables which had a $p \leq 0.10$ in univariable analyses were fitted together in an initial multivariable model; (ii) variables which had a $p \leq 0.05$ in this initial model were retained and considered the core model; (iii) variables which were not statistically significant in the core model, or univariable analyses, were fitted individually to the core model and significance checked using likelihood ratio test; any with a $p$ value of $\leq 0.05$ were retained. In developing the model, we excluded survivors with missing information (providing the percentage missing was $<5 \%$ ) and those whose treatment was classified as "other" (which included chemotherapy only or unknown treatment). Throughout the model fitting process, we took care to avoid multicollinearity. Variables in the final model had a variance inflation factor $<10$ and tolerance $>0.1$. The final model had adequate fit (goodness-of-fit test: $p=0.533$ ) [38].

\section{Results}

\section{Study sample}

Overall, 3348 PCa survivors responded to the questionnaire (response rate $=54 \%$ ). Of these, 2458 provided complete data on CRF and financial stress and comprised the current study population. When this study population was compared with the respondents excluded because of incomplete data on CRF and financial stress $(n=890)$, the study population were younger at diagnosis, more often from RoI, and more often working at diagnosis; they more often had early disease and less often were on ADT ( $\chi^{2}$ tests: all $\left.p<0.001\right)$; they more often had completed higher education $(p$ for trend $<0.001)$ and less often had comorbidities ( $\chi^{2}$ test: $\left.p<0.001\right)$. There was no significant difference in terms of time since diagnosis $(p=$ 0.369).

Of the 2458 participants, the majority were from RoI $(81.5 \%)$, at least 60 years of age at cancer diagnosis $(71.1 \%)$, married/living with a partner $(83.3 \%)$ and had completed only school-level education (69.4\%). Around half were diagnosed with early disease $(52.5 \%)$ and were within 5 years of diagnosis at survey $(47.8 \%)$ (Table 1).

\section{Financial stress}

Overall, 538 (21.9\%) reported pre-diagnosis financial stress and $587(23.9 \%)$ reported post-diagnosis financial stress. When these were considered together, 268 (10.9\%) reported pre-diagnosis financial stress only, 317 (12.9\%) had postdiagnosis financial stress only and $270(11.0 \%)$ reported both (cumulative financial stress); around two thirds had neither pre- nor post-diagnosis financial stress (Table 1). Prediagnosis stress only was more common among those with primary education than secondary or tertiary education; those working at diagnosis more often reported post-diagnosis stress than those who were not working; and prevalence of cumulative stress was higher in those $<60$, resident in RoI and living alone at diagnosis, with comorbidities, without early disease (Supplementary Table 1; Fig. 1a-f).

\section{Prevalence and factors associated with clinically important CRF}

Of the 2458 participants, $470(19.1 \%)$ scored in the range for clinically important $\mathrm{CRF}$ at the time of questionnaire 
Table 1 Study characteristics of prostate cancer survivors included in the analysis. $N=2458$

\begin{tabular}{|c|c|}
\hline & $n(\%)$ \\
\hline \multicolumn{2}{|l|}{ Financial stress } \\
\hline No & $1603(65.2)$ \\
\hline Pre-diagnosis only & $268(10.9)$ \\
\hline Post-diagnosis only & $317(12.9)$ \\
\hline Cumulative $^{\mathrm{a}}$ & $270(11.0)$ \\
\hline \multicolumn{2}{|l|}{ Age at diagnosis, years } \\
\hline$\leq 59$ & $710(28.9)$ \\
\hline $60-69$ & $1199(48.8)$ \\
\hline$\geq 70$ & $549(22.3)$ \\
\hline \multicolumn{2}{|l|}{ Jurisdiction } \\
\hline RoI & $2002(81.5)$ \\
\hline NI & $456(18.5)$ \\
\hline \multicolumn{2}{|l|}{ Marital status at diagnosis } \\
\hline Married/living with a partner & $2047(83.3)$ \\
\hline Other & $394(16.0)$ \\
\hline Not reported & $17(0.7)$ \\
\hline \multicolumn{2}{|l|}{ Living alone at diagnosis } \\
\hline No & $2147(87.4)$ \\
\hline Yes & $289(11.8)$ \\
\hline Not reported & $22(0.9)$ \\
\hline \multicolumn{2}{|l|}{ Highest level of education at diagnosis } \\
\hline Primary & $791(32.2)$ \\
\hline Secondary & $914(37.2)$ \\
\hline$\geq$ Tertiary & $675(27.4)$ \\
\hline Not reported & $78(3.2)$ \\
\hline \multicolumn{2}{|c|}{ Employment status, immediately before diagnosis } \\
\hline Working & $1322(53.8)$ \\
\hline Not working/other & $1039(42.3)$ \\
\hline Not reported & $97(3.9)$ \\
\hline \multicolumn{2}{|l|}{ Comorbidities at diagnosis } \\
\hline No & $1148(46.7)$ \\
\hline Yes & $1310(53.3)$ \\
\hline \multicolumn{2}{|l|}{ Extent of disease at diagnosis ${ }^{\mathrm{b}}$} \\
\hline Early & $1290(52.5)$ \\
\hline Late & $458(18.6)$ \\
\hline Unknown & $710(28.9)$ \\
\hline \multicolumn{2}{|l|}{ Treatment $^{\mathrm{c}}$} \\
\hline $\mathrm{RP}$ & $802(32.6)$ \\
\hline EBRT & $1219(49.6)$ \\
\hline BT & $109(4.4)$ \\
\hline ADT & $177(7.2)$ \\
\hline Active surveillance/watchful-waiting & $104(4.2)$ \\
\hline Other & 47 (1.9) \\
\hline \multicolumn{2}{|l|}{ Time since diagnosis, years } \\
\hline $2-5$ & $1174(47.8)$ \\
\hline $5-10$ & $786(32.0)$ \\
\hline$\geq 10$ & $498(20.2)$ \\
\hline
\end{tabular}

${ }^{a}$ Experienced both pre-diagnosis and post-diagnosis financial stress

${ }^{\mathrm{b}}$ Early (localised disease: stage I/II and Gleason score 2-7 at diagnosis), late (locally advanced/advanced disease: III/IV and any Gleason score at diagnosis), unknown extent (other combinations of stage and Gleason score, or unknown stage or Gleason score)

${ }^{\mathrm{c}}$ Primary treatment(s): a hierarchical variable defined as (i) RP at any time following diagnosis (with/without other treatments); (ii) EBRT with/without concurrent ADT; (iii) BT without previous RP or EBRT; (iv) ADT alone without RP, EBRT or BT; (v) active surveillance/ watchful-waiting; and (vi) other (which includes chemotherapy (2 participants) and unknown treatment (45 participants))

$R o I$ the Republic of Ireland; NI Northern Ireland; $R P$ radical prostatectomy; $E B R T$ external beam radiotherapy; $B T$ brachytherapy; $A D T$ androgen deprivation therapy

completion. Survivors with financial stress exposure reported clinically important CRF significantly more often compared with those without financial stress; there was a linear trend across categories of financial stress (\% reporting CRF: no financial stress, $12.2 \%$; pre-diagnosis financial stress only, $20.5 \%$; post-diagnosis financial stress only, $32.5 \%$; cumulative financial stress, $43.3 \%$; $p$ for trend $<0.001$ ) (Table 2). Other variables significantly associated $\left(\chi^{2} p \leq 0.05\right)$ with clinically important CRF were age at diagnosis, jurisdiction, level of education, employment status at time of diagnosis, presence of comorbidities, disease extent and treatment received (Table 2).

After controlling for significant demographic and clinical confounders in the multivariable model, the association between financial stress exposure and CRF persisted. There was suggestion of a dose-response relationship whereby the risk of CRF increased with increasing financial stress (OR = $1.83,95 \%$ CI $1.27-2.65, p=0.001$ for pre-diagnosis financial stress only; $\mathrm{OR}=4.11,95 \%$ CI $3.01-5.61, p<0.001$ for postdiagnosis financial stress only; and $\mathrm{OR}=4.58,95 \%$ CI 3.30 $6.35, p<0.001$ for cumulative financial stress) (Table 3).

As regards other factors, living in NI $(\mathrm{OR}=1.45,95 \% \mathrm{CI}$ 1.07-1.96), not working at diagnosis $(1.62,1.23-2.12)$, having comorbidities $(1.76,1.39-2.24)$, having late disease (1.61, 1.20-2.1), having received EBRT $(1.57,1.17-2.09)$ or ADT $(2.58,1.64-4.05)$ and having cancer diagnosed $\geq 10$ years before the survey $(1.44,1.06-1.95)$ were significantly associated with a higher risk of CRF. Those who were 60-69 years of age at diagnosis $(0.68,0.51-0.92)$ and had at least tertiary level education $(0.63,0.46-0.86)$ had lower risk of CRF (Table 3 ).

\section{Discussion}

Our results suggest that both clinically important CRF and financial stress are common problems for PCa survivors, even those who are several years from diagnosis. When present, CRF was strongly associated with financial stress, with a suggestion of a dose-response relationship such that survivors who experienced both pre-diagnosis and post-diagnosis financial stress had almost 5 times higher risk of CRF than those without financial stress; this relationship was not explained by socio-demographic and clinical differences between those with and without financial stress.

\section{Prevalence of financial hardship}

There is growing recognition of the issue of financial stress, hardship or toxicity, among cancer survivors, including those with PCa $[22,39,40]$. In the current study, almost one quarter of PCa survivors (23.9\%) reported post-diagnosis financial stress as a result of the cancer. It is difficult to compare prevalence across studies as investigators have rarely used the same questions/instruments to assess hardship. Moreover, the wider context within which the studies have been undertaken varies substantially. Both healthcare and social welfare systems, and 
Fig. 1 Prevalence of financial stress by key socio-demographic and clinical variables. a Age at diagnosis. b Highest level of education completed at diagnosis. c Living alone at diagnosis. $\mathbf{d}$ Employment status at diagnosis. e Comorbidities at diagnosis. $\mathbf{f}$ Extent of disease at diagnosis (a) Age at diagnosis

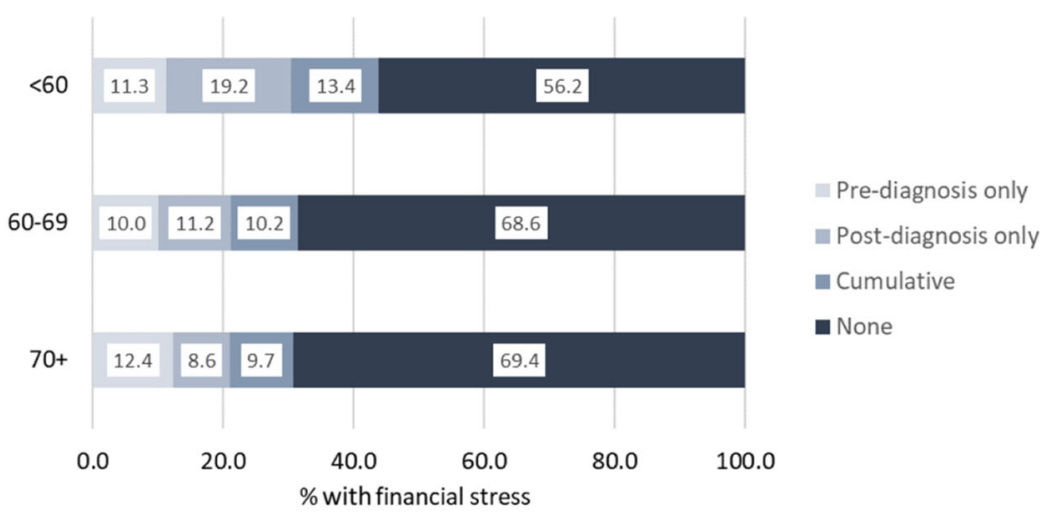

(b) Highest level of education completed at diagnosis

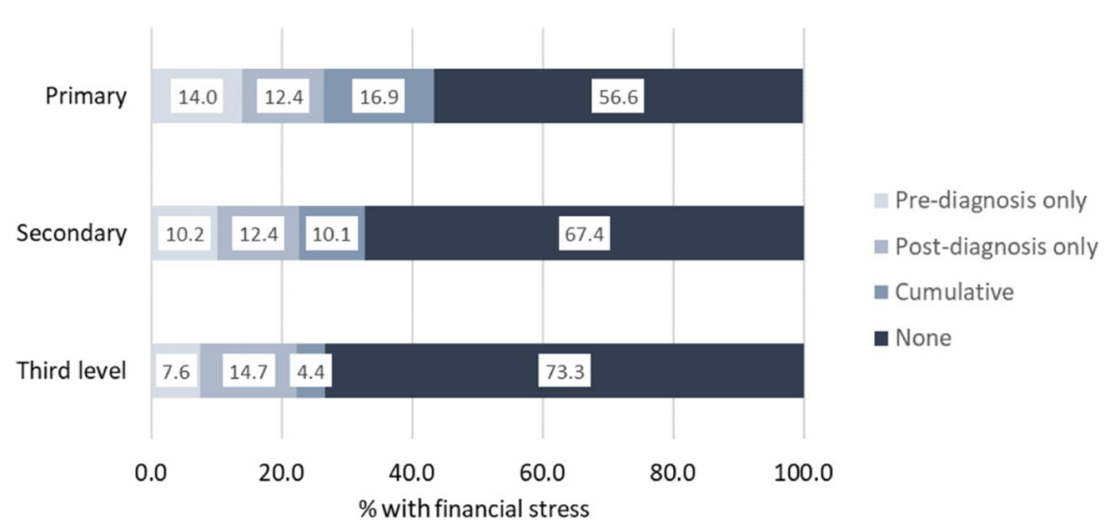

(c) Living alone at diagnosis

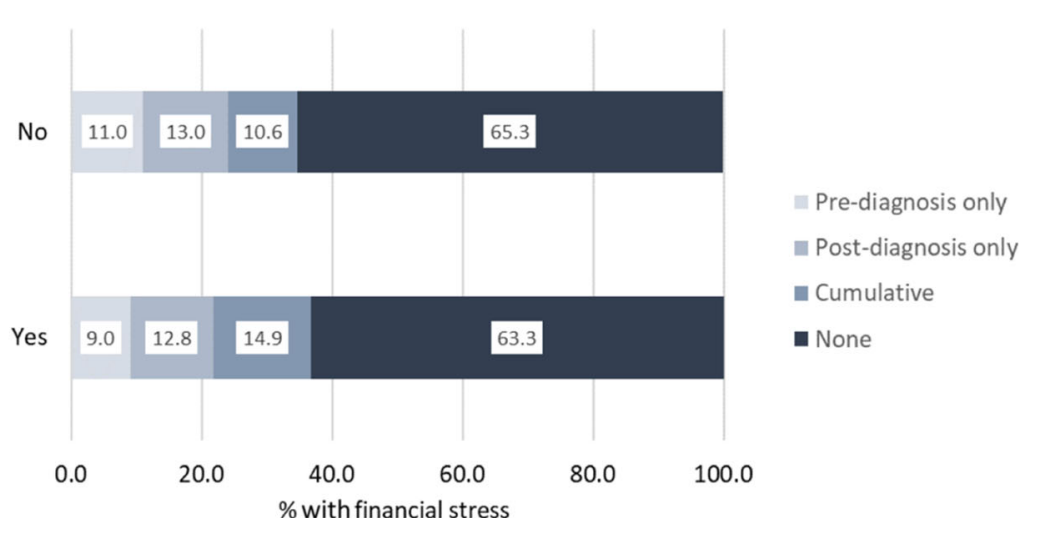

employment legislation, will influence the likelihood that an individual experiences material financial stress due to cancer, since these affect, for example, the extent to which patients may incur cancer-related out-of-pocket costs and their entitlement to compensation for lost income when absent from work due to cancer. The prevalence of cancer-related financial stress in the current study is lower than that in previous studies of survivors of other types of cancer in RoI which used the same question (colorectal cancer, $41 \%$; head and neck cancer, $51 \%$; breast cancer, $51 \%$ )
$[23,37,41]$. This is likely to be a function of, on average, the higher socio-economic status of men diagnosed with PCa [42] which may provide, for many, a buffer against financial stress due to cancer - and the fact that this study population largely comprised longer-term survivors. Cancer-related financial hardship may lessen over time as survivors return to work and their income is restored and they ceased to have as many cancerrelated out-of-pocket expenses (although empirical data is lacking on this) or they retire as they age. 
(d) Employment status at diagnosis

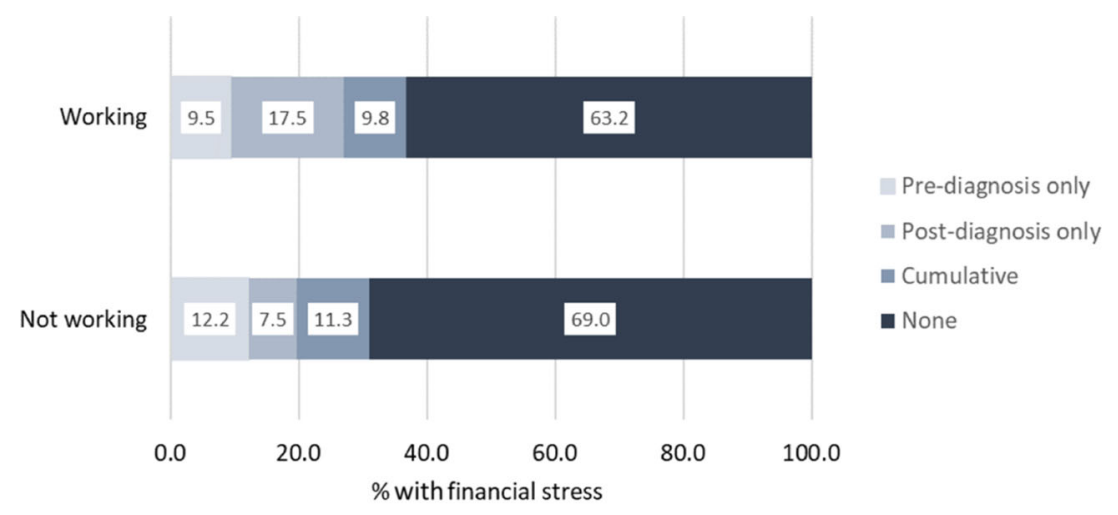

(e) Comorbidities at diagnosis

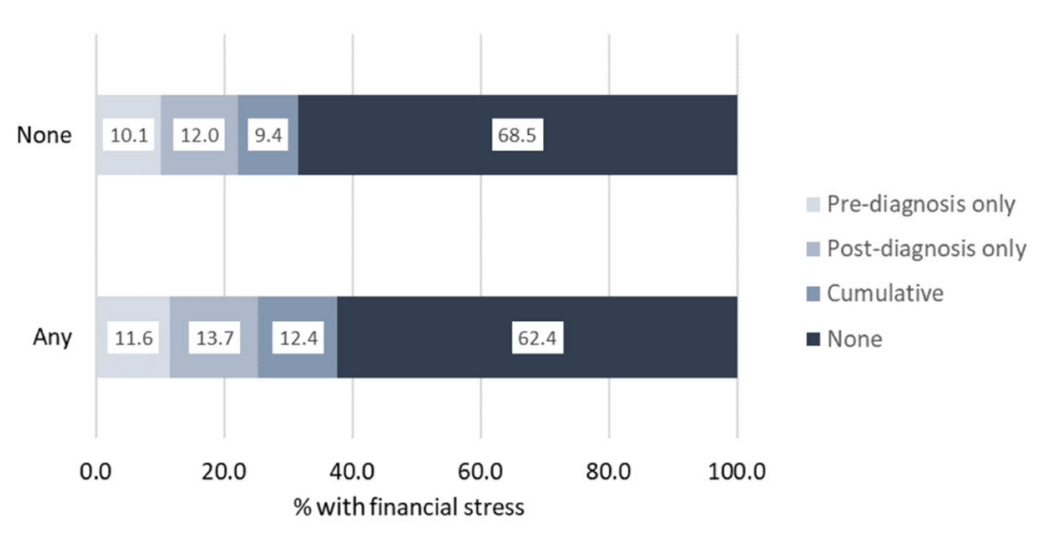

(f) Extent of disease at diagnosis

Fig. 1 (continued)

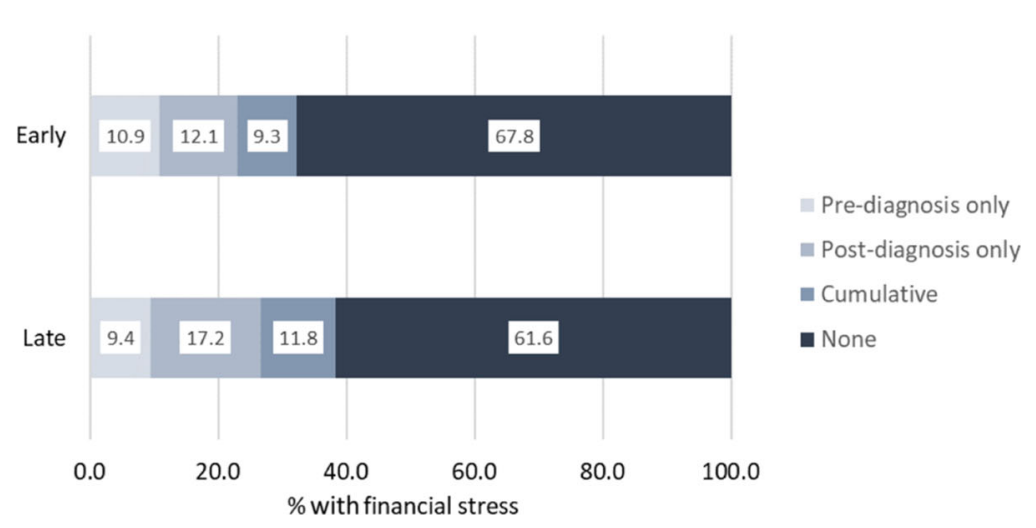

\section{Financial hardship and CRF}

The primary focus of the current study was not financial hardship per se but rather its association with clinically significant CRF. While there is a growing awareness of the link between cancer-related financial hardship and HRQoL among survivors [23, 28, 43], there has been much less investigation of associations between hardship and cancer-related symptoms. A recent systematic review reported that six studies have found relationships between financial toxicity and depression and three have reported relationships with anxiety [39]. In terms of physical symptoms, a large US study of colorectal and lung cancer found that financial toxicity was an independent predictor of cancer-related pain at 4 and 12 months postdiagnosis [44], while a study in France of a mixed group of cancers found a significant relationship between financial toxicity and overall physical symptom burden [45] Our results extend these by suggesting a relationship between financial 
Table 2 Univariable analysis - associations between financial stress, demographic and clinical variables and cancer-related fatigue: $p$ values from $\chi^{2}$ tests, odds ratios (ORs), 95\% confidence intervals (CIs) and $p$ values from tests of significance

\begin{tabular}{|c|c|c|c|c|c|}
\hline & \multicolumn{5}{|c|}{ Cancer-related fatigue } \\
\hline & $\begin{array}{l}\text { Yes }(n=470) \\
n(\%)\end{array}$ & $\begin{array}{l}\text { No }(n=1988) \\
n(\%)\end{array}$ & $p^{\mathrm{a}}$ & OR $(95 \% \mathrm{CI})$ & $p$ \\
\hline \multicolumn{6}{|l|}{ Financial stress } \\
\hline No & $195(12.2)$ & $1408(87.8)$ & \multirow[t]{4}{*}{$<0.001^{\mathrm{b}}$} & 1.00 & - \\
\hline Pre-diagnosis only & $55(20.5)$ & $213(79.5)$ & & $1.86(1.34-2.60)$ & $<0.001$ \\
\hline Post-diagnosis only & $103(32.5)$ & $214(67.5)$ & & $3.48(2.63-4.59)$ & $<0.001$ \\
\hline Cumulative $^{\mathrm{c}}$ & $117(43.3)$ & $153(56.7)$ & & $5.52(4.16-7.33)$ & $<0.001$ \\
\hline \multicolumn{6}{|l|}{ Age at diagnosis, years } \\
\hline$\leq 59$ & $139(19.6)$ & $571(80.4)$ & \multirow[t]{3}{*}{$0.032^{\mathrm{b}}$} & 1.00 & - \\
\hline $60-69$ & $193(16.1)$ & $1006(83.9)$ & & $0.79(0.62-1.00)$ & 0.053 \\
\hline$\geq 70$ & $138(25.1)$ & $411(74.9)$ & & $1.38(1.06-1.80)$ & 0.018 \\
\hline \multicolumn{6}{|l|}{ Jurisdiction } \\
\hline RoI & $364(18.2)$ & $1638(81.8)$ & \multirow[t]{2}{*}{0.013} & 1.00 & - \\
\hline NI & $106(23.3)$ & $350(76.7)$ & & $1.36(1.07-1.74)$ & 0.013 \\
\hline \multicolumn{6}{|l|}{ Marital status at diagnosis } \\
\hline Married/ living with a partner & $378(18.5)$ & $1669(81.5)$ & \multirow[t]{2}{*}{0.057} & 1.00 & - \\
\hline Other & $89(22.6)$ & $305(77.4)$ & & $1.29(0.99-1.67)$ & 0.057 \\
\hline \multicolumn{6}{|l|}{ Living alone at diagnosis } \\
\hline No & $401(18.7)$ & $1746(81.3)$ & \multirow[t]{2}{*}{0.092} & 1.00 & - \\
\hline Yes & $66(22.8)$ & $223(77.2)$ & & $1.29(0.96-1.73)$ & 0.092 \\
\hline \multicolumn{6}{|l|}{ Highest level of education at diagnosis } \\
\hline Primary & $192(24.3)$ & $599(75.7)$ & \multirow[t]{3}{*}{$<0.001^{\mathrm{b}}$} & 1.00 & - \\
\hline Secondary & $171(18.7)$ & $743(81.3)$ & & $0.72(0.57-0.91)$ & 0.005 \\
\hline$\geq$ Tertiary & $92(13.6)$ & $583(86.4)$ & & $0.49(0.37-0.65)$ & $<0.001$ \\
\hline \multicolumn{6}{|c|}{ Employment status, immediately before diagnosis } \\
\hline Working & $208(15.7)$ & $1114(84.3)$ & \multirow[t]{2}{*}{$<0.001$} & 1.00 & - \\
\hline Not working/other & $233(22.4)$ & $806(77.6)$ & & $1.55(1.26-1.91)$ & $<0.001$ \\
\hline \multicolumn{6}{|l|}{ Comorbidities at diagnosis } \\
\hline None & $157(13.7)$ & $991(86.3)$ & \multirow[t]{2}{*}{$<0.001$} & 1.00 & - \\
\hline Any & $313(23.9)$ & $997(76.1)$ & & $1.98(1.60-2.45)$ & $<0.001$ \\
\hline \multicolumn{6}{|l|}{ Extent of disease at diagnosis ${ }^{\mathrm{d}}$} \\
\hline Early & $210(16.3)$ & $1080(83.7)$ & \multirow[t]{3}{*}{$<0.001$} & 1.00 & - \\
\hline Late & $117(25.6)$ & $341(74.4)$ & & $1.76(1.36-2.28)$ & $<0.001$ \\
\hline Unknown & $143(20.1)$ & $567(79.9)$ & & $1.30(1.02-1.64)$ & 0.030 \\
\hline \multicolumn{6}{|l|}{ Treatment $^{\mathrm{e}}$} \\
\hline $\mathrm{RP}$ & $115(14.3)$ & $687(85.7)$ & \multirow[t]{5}{*}{$<0.001$} & 1.00 & - \\
\hline EBRT & $265(21.7)$ & $954(78.3)$ & & $1.66(1.31-2.11)$ & $<0.001$ \\
\hline BT & $11(10.1)$ & $98(89.9)$ & & $0.67(0.35-1.29)$ & 0.231 \\
\hline ADT & $58(32.8)$ & $119(67.2)$ & & $2.91(2.01-4.22)$ & $<0.001$ \\
\hline Active surveillance/watchful-waiting & $15(14.4)$ & $89(85.6)$ & & $1.01(0.56-1.80)$ & 0.982 \\
\hline \multicolumn{6}{|l|}{ Time since diagnosis, years } \\
\hline $2-5$ & $233(19.9)$ & $941(80.1)$ & \multirow[t]{3}{*}{0.061} & 1.00 & - \\
\hline $5-10$ & $130(16.5)$ & $656(83.5)$ & & $0.80(0.63-1.01)$ & 0.065 \\
\hline$\geq 10$ & $107(21.5)$ & $391(78.5)$ & & $1.11(0.85-1.43)$ & 0.446 \\
\hline
\end{tabular}

${ }^{a} \chi^{2}$ test; unknown group is excluded if $<5 \%$ has missing data; other treatment group is excluded

${ }^{\mathrm{b}} p$ for trend

${ }^{\mathrm{c}}$ Experienced both pre-diagnosis and post-diagnosis financial stress

${ }^{\mathrm{d}}$ Early (localised disease: stage I/II and Gleason score 2-7 at diagnosis), late (locally advanced/advanced disease: III/IV and any Gleason score at diagnosis), unknown extent (other combinations of stage and Gleason score, or unknown stage or Gleason score)

${ }^{\mathrm{e}}$ Hierarchical variable based on primary treatment(s) reported

$R o I$ the Republic of Ireland; NI Northern Ireland; $R P$ radical prostatectomy; $E B R T$ external beam radiotherapy; $B T$ brachytherapy; $A D T$ androgen deprivation therapy

hardship and CRF and - moreover - that those with financial stress before diagnosis who then experience cancer-related financial stress have substantially increased risk of CRF. CRF has a profound impact on PCa survivors' lives, and is a major determinant of QoL [46, 47]. Studies on cancer-related symptoms, such as this one, are starting to suggest pathways by which financial hardship may lead to reduced QoL among survivors. 
Table 3 Multivariable logistic regression analysis - financial stress and demographic and clinical variables significantly associated with cancer-related fatigue: odds ratios (ORs) with $95 \%$ confidence intervals (CIs) and $p$ values

\begin{tabular}{|c|c|c|c|}
\hline & \multicolumn{2}{|c|}{ Multivariable analyses $^{\mathrm{a}}$} & \multirow[t]{2}{*}{$p^{\mathrm{b}}$} \\
\hline & OR $(95 \% \mathrm{CI})$ & $p$ & \\
\hline Financial stress & & & $<0.001$ \\
\hline No & 1.00 & - & \\
\hline Pre-diagnosis only & $1.83(1.27-2.65)$ & 0.001 & \\
\hline Post-diagnosis only & $4.11(3.01-5.61)$ & $<0.001$ & \\
\hline Cumulative $^{c}$ & $4.58(3.30-6.35)$ & $<0.001$ & \\
\hline Age at diagnosis, years & & & 0.007 \\
\hline$\leq 59$ & 1.00 & - & \\
\hline $60-69$ & $0.68(0.51-0.92)$ & 0.011 & \\
\hline$\geq 70$ & $0.98(0.67-1.44)$ & 0.918 & \\
\hline Jurisdiction & & & 0.020 \\
\hline RoI & 1.00 & - & \\
\hline NI & $1.45(1.07-1.96)$ & 0.016 & \\
\hline Highest level of education at diagnosis & & & 0.006 \\
\hline Primary & 1.00 & - & \\
\hline Secondary & $0.97(0.75-1.27)$ & 0.836 & \\
\hline$\geq$ Tertiary & $0.63(0.46-0.86)$ & 0.004 & \\
\hline Employment status, immediately before diagnosis & & & 0.001 \\
\hline Working & 1.00 & - & \\
\hline Not working/other & $1.62(1.23-2.12)$ & $<0.001$ & \\
\hline Comorbidities at diagnosis & & & $<0.001$ \\
\hline None & 1.00 & - & \\
\hline Any & $1.76(1.39-2.24)$ & $<0.001$ & \\
\hline Extent of disease at diagnosis ${ }^{\mathrm{d}}$ & & & 0.005 \\
\hline Early & 1.00 & - & \\
\hline Late & $1.61(1.20-2.16)$ & 0.002 & \\
\hline Unknown & $1.03(0.78-1.36)$ & 0.829 & \\
\hline Treatment $^{\mathrm{e}}$ & & & 0.001 \\
\hline $\mathrm{RP}$ & 1.00 & - & \\
\hline EBRT & $1.57(1.17-2.09)$ & 0.002 & \\
\hline BT & $1.04(0.49-2.20)$ & 0.927 & \\
\hline ADT & $2.58(1.64-4.05)$ & $<0.001$ & \\
\hline Active surveillance/watchful-waiting & $1.13(0.57-2.25)$ & 0.718 & \\
\hline Time since diagnosis, years & & & 0.007 \\
\hline $2-5$ & 1.00 & - & \\
\hline $5-10$ & $0.85(0.65-1.12)$ & 0.251 & \\
\hline$\geq 10$ & $1.44(1.06-1.95)$ & 0.020 & \\
\hline
\end{tabular}

${ }^{\text {a }}$ Unknown group was excluded if it was less than $5 \%$

${ }^{\mathrm{b}}$ From likelihood-ratio test

${ }^{\mathrm{c}}$ Experienced both pre-diagnosis and post-diagnosis financial stress

${ }^{\mathrm{d}}$ Early (localised disease: stage I/II and Gleason score 2-7 at diagnosis), late (locally advanced/advanced disease: III/IV and any Gleason score at diagnosis), unknown extent (other combinations of stage and Gleason score, or unknown stage or Gleason score)

${ }^{\mathrm{e}}$ Hierarchical variable based on primary treatment(s) reported

$R o I$ the Republic of Ireland; NI Northern Ireland; $R P$ radical prostatectomy; $E B R T$ external beam radiotherapy; $B T$ brachytherapy; $A D T$ androgen deprivation therapy
In terms of explanations for our findings, experiencing cancer-related symptoms (including fatigue and pain) can hamper cancer survivors' ability to work, and increase their risk of unemployment and early retirement [48-51]. This 
suggests that the effects of CRF on work participation may, at least in part, explain our findings. Being at work is important for maintaining income in cancer survivors, and those who are absent from work due to cancer, or have to retire early, are likely to have a drop in income. Previous research in Ireland shows that many survivors (including those with PCa) do not receive financial compensation for time away from work due to the cancer and experience a drop in income post-diagnosis $[52,53]$. A drop in income - due to an inability to work as a result of cancer-related symptoms (such as CRF) — could lead to post-diagnosis financial stress. Having noted this, only around half of survivors in the current study were working at diagnosis and less than three quarters of those working took time off. So it seems unlikely that this can entirely explain our findings.

Evidence suggests that physical activity and/or psychological interventions are effective in alleviating $\mathrm{CRF}[54,55]$ and guidelines recommend somewhat different approaches depending on whether the individual is on active treatment, is post-treatment or at end-of-life. It is possible that survivors who experience financial stress may have reduced access to such interventions, either directly (i.e. for those interventions that require survivors to pay for them) or indirectly (because of reduced access to the healthcare services that would provide a route to the interventions). For example, pharmacological intervention would be likely to be prescribed by GPs and, in the RoI, most individuals make co-payments to be seen by a GP and pay the full cost of prescribed medications; those experiencing financial stress may struggle to make these payments. This provides another possible explanation for our findings.

In the general population, material hardship - at both the individual and household level — is associated with worse selfrated health [56, 57]. Moreover, self-rated health and fatigue are strongly inversely related [58]. Although CRF is different from fatigue that is not associated with cancer, it is noteworthy that our observations about CRF among PCa survivors broadly reflect patterns in the general population.

In terms of how financial distress may lead to CRF, it is established that psychological distress is a predictor of CRF in $\mathrm{PCa}$ survivors [59]. There are inter-relationships between the economic impact of cancer on the individual and the emotional distress they experience $[60,61]$. Thus, a possible pathway may involve financial stress influencing emotional distress and that then influencing CRF.

Current research on the biological mechanisms of CRF suggests an important role for proinflammatory cytokines, which contribute to several relevant pathways (e.g. neuroendocrine-immune signalling) $[62,63]$. Factors such as financial stressors, depression and elevated distress can influence inflammation activity and - potentially - contribute to CRF [63]. This is thus a possible underlying mechanism for the associations observed here. Of course, this is speculative and empirical work measuring inflammation activity in survivors with and without financial stress would be valuable.

\section{Other risk factors for CRF}

In terms of other risk factors for CRF, comparisons with other studies are complicated by the fact that these generally included people with other types of cancer or selected groups of $\mathrm{PCa}$ survivors; treatment is a key determinant of CRF [9] and, of course, treatment varies by cancer site and extent of disease. A further complication is that studies have used different instruments to assess CRF. Having said that, there are some consistencies between our findings and others. For example, previous studies, in breast, colorectal and prostate cancer, have reported increased risk of CRF in survivors who have comorbidities $[14,64,65]$. However, findings regarding educational level and CRF are more inconsistent [14, 64, 66, 67].

In the current study, very-long-term survivors $(\geq 10$ years from diagnosis) had a $44 \%$ increased risk of CRF. These survivors may be more likely to have been discharged from hospital-based follow-up and therefore not be in regular contact with health professionals who might be able to help manage CRF. This group of survivors were also older at the time of questionnaire completion. Previous work has shown that older survivors report higher levels of fatigue, and that both cancer-related and age-related factors contribute to this [68].

\section{Limitations}

There are several limitations in our study. Compared to the entire population of $\mathrm{PCa}$ survivors on the island of Ireland, among respondents, older men ( $70+$ at diagnosis) were underrepresented and shorter-term survivors (2-4.99 years from diagnosis) were over-represented [33]. In the current analysis, the study population was younger at diagnosis, more often from RoI and more often had early-stage disease than respondents who did not provide complete data on CRF and financial stress. It is therefore possible that the overall estimates of the prevalence of CRF and financial hardship were biased. For example, since financial stress was less commonly reported among younger survivors, we may have overestimated the overall prevalence of financial stress. In contrast, because CRF was more common among older survivors, the overall prevalence of CRF may be underestimated.

Both financial stress and clinically important CRF were based on self-report. The former was assessed using questions that have previously been found to have convergent validity with objective measures of financial burden in cancer survivors in Ireland $[28,41]$. However, we did not have data on individual financial stressors or measurements of financial stress over time. Moreover, it is likely that there is some inaccuracy in participants' recall of whether they experienced financial stress; this will have resulted in misclassification. CRF 
was measured using a validated HRQoL instrument and a cutoff that has been validated for clinically important fatigue $[35,36]$. However, the EORTC QLQ-C30 fatigue subscale includes only three questions. Other more extensive tools are available which, for example, distinguish different manifestations of CRF (e.g. physical, emotional, cognitive) and/or assess the extent to which CRF interferes with daily life [69, 70]. The possibility cannot be excluded that our results would have differed had we used one of these instruments. Research investigating relationships between the financial impact of $\mathrm{PCa}$ and different aspects of CRF would be valuable.

As with any report of an association between two variables, it is possible that the results may be affected by uncontrolled confounding. In this case, the lack of previous investigations of financial stress and CRF make it difficult to speculate as to what uncontrolled confounders could explain, in full or in part, the results. We lacked information on some potential influences on CRF, such as chemotherapy receipt [46] at time of survey completion. While only two participants had had chemotherapy as initial treatment for their prostate cancer, it is possible that some were undergoing chemotherapy at the time of survey completion because their disease had progressed. If chemotherapy receipt was more common in those reporting financial stress, this could have impacted our findings. Finally, as the distributions of potential determinants of CRF vary across different populations, our findings may not be generalised to other populations.

\section{Implications}

Our findings imply that screening for financial stress may help identify survivors at higher risk of CRF during and after treatment. In the USA, screening for financial toxicity among cancer patients has been advocated [71] and a recently developed measure of financial toxicity [72] might be useful in this regard. Such screening would be valuable on its own account as it would help identify those who might benefit from financial support and advice, but it is also possible that interventions to prevent or ameliorate CRF may be more effective if either they are targeted towards those experiencing (or at risk of) financial distress or measures are first taken to help survivors address financial stress.

In an ideal world, survivors would be fully protected from, or compensated for, cancer-related financial stress, but this may be unrealistic in lean economic times. Measures that may be more feasible — but still helpfulinclude financial and/or welfare advice services, especially if these have specific cancer expertise, and support funds which assist with treatment-related travel or accommodation costs [73-76]. Other useful initiatives include training and resources for employers to enable them to support survivors to return to work [77].
As regards research, there is a need for longitudinal studies of cancer-related financial stress, its determinants and its relationship with CRF (and other cancer-related symptoms), and inter-relationships with emotional distress and HRQoL among well-defined PCa survivor populations. Such studies are needed in settings with different healthcare and social welfare provisions, since findings from one context may not easily generalise to another.

\section{Conclusions}

In conclusion, our findings show that both clinically important $\mathrm{CRF}$ and financial stress are common problems for PCa survivors, even those who are several years from diagnosis. Moreover, cumulative financial stress exposure may be an independent risk factor for CRF among PCa survivors. There may be benefits in targeting interventions for reducing CRF towards survivors with financial stress, or developing strategies to reduce financial stress among survivors.

Acknowledgements The authors thank the healthcare professionals who facilitated the PiCTure study; members of Men Against Cancer (MAC) and local cancer support groups who assisted with survey pre-testing; Dr. Heather Kinnear for managing the survey in NI, Joanne Clooney, Claire O'Callaghan and Audrey Craven-Lynn for survey administration and clerical support; Jenalee Kennedy, Patricia McDowell and Jonathan Mitchell for data entry; Sandra Deady and Colin Fox for providing cancer registration data; registration, data and IT staff in the registries; and, most importantly, the men who participated.

Funding information Data collection was funded by grants from the Health Research Board (HRA_HSR/2010/17), Prostate Cancer UK (NI09-03 and NI-PG13-001) and Northern Ireland R\&D, with additional support from the National Cancer Control Programme in RoI. The analysis was supported by Newcastle University.

\section{Compliance with ethical standards}

The study was approved by the Irish College of General Practitioners for RoI, and the Office for Research Ethics Committee NI. Participants provided signed informed consent.

Conflict of interest The authors declare that they have no conflict of interest.

Open Access This article is licensed under a Creative Commons Attribution 4.0 International License, which permits use, sharing, adaptation, distribution and reproduction in any medium or format, as long as you give appropriate credit to the original author(s) and the source, provide a link to the Creative Commons licence, and indicate if changes were made. The images or other third party material in this article are included in the article's Creative Commons licence, unless indicated otherwise in a credit line to the material. If material is not included in the article's Creative Commons licence and your intended use is not permitted by statutory regulation or exceeds the permitted use, you will need to obtain permission directly from the copyright holder. To view a copy of this licence, visit http://creativecommons.org/licenses/by/4.0/. 


\section{References}

1. Bray F, Ferlay J, Soerjomataram I, Siegel RL, Torre LA, Jemal A. Global cancer statistics 2018: GLOBOCAN estimates of incidence and mortality worldwide for 36 cancers in 185 countries. CA Cancer J Clin. 2018;68(6):394-424.

2. Allemani C, Matsuda T, Di Carlo V, Harewood R, Matz M, Nikšić $\mathrm{M}$, et al. Global surveillance of trends in cancer survival 2000-14 (CONCORD-3): analysis of individual records for 37513025 patients diagnosed with one of 18 cancers from 322 population-based registries in 71 countries. Lancet. 2018;391(10125):1023-75.

3. DeSantis CE, Lin CC, Mariotto AB, Siegel RL, Stein KD, Kramer JL, et al. Cancer treatment and survivorship statistics, 2014. CA Cancer J Clin. 2014;64(4):252-71.

4. Maddams J, Brewster D, Gavin A, Steward J, Elliott J, Utley M, et al. Cancer prevalence in the United Kingdom: estimates for 2008. Br J Cancer. 2009;101(3):541-7.

5. Sharp L, Deady S, Gallagher P, Molcho M, Pearce A, Thomas AA, et al. The magnitude and characteristics of the population of cancer survivors: using population-based estimates of cancer prevalence to inform service planning for survivorship care. BMC Cancer. 2014;14:767. https://doi.org/10.1186/1471-2407-14-767.

6. Maddams J, Utley M, Møller H. Projections of cancer prevalence in the United Kingdom, 2010-2040. Br J Cancer. 2012;107(7):1195202.

7. Mock V. Fatigue management: evidence and guidelines for practice. Cancer. 2001;92(6 Suppl):1699-7077.

8. Storey DJ, McLaren DB, Atkinson MA, Butcher I, Frew LC, Smyth JF, et al. Clinically relevant fatigue in men with hormonesensitive prostate cancer on long-term androgen deprivation therapy. Ann Oncol. 2012;23(6):1542-9. https://doi.org/10.1093/ annonc/mdr447.

9. Langston B, Armes J, Levy A, Tidey E, Ream E. The prevalence and severity of fatigue in men with prostate cancer: a systematic review of the literature. Support Care Cancer. 2013;21(6):1761-71. https://doi.org/10.1007/s00520-013-1751-5.

10. Baguley BJ, Bolam KA, Wright ORL, Skinner TL. The effect of nutrition therapy and exercise on cancer-related fatigue and quality of life in men with prostate cancer: a systematic review. Nutrients. 2017;9(9):1003.

11. Drummond FJ, Kinnear H, O'Leary E, Donnelly GA, Sharp L. Long-term health-related quality of life of prostate cancer survivors varies by primary treatment. Results from the PiCTure (Prostate Cancer Treatment, your experience) study. J Cancer Surviv. 2015;9(2):361-72. https://doi.org/10.1007/s11764-014-0419-6.

12. Wilding S, Downing A, Wright L, Selby P, Watson E, Wagland R, et al. Cancer-related symptoms, mental well-being, and psychological distress in men diagnosed with prostate cancer treated with androgen deprivation therapy. Qual Life Res. 28(10):2741-51.

13. Curt GA, Breitbart W, Cella D, Groopman JE, Horning SJ, Itri LM, et al. Impact of cancer-related fatigue on the lives of patients: new findings from the fatigue coalition. Oncologist. 2000;5(5):353-60.

14. Bower JE, Ganz PA, Desmond KA, Bernaards C, Rowland JH, Meyerowitz BE, et al. Fatigue in long-term breast carcinoma survivors: a longitudinal investigation. Cancer. 2006;106(4):751-8.

15. Bower JE, Ganz PA, Desmond KA, Rowland JH, Meyerowitz BE, Belin TR. Fatigue in breast cancer survivors: occurrence, correlates, and impact on quality of life. J Clin Oncol. 2000;18(4):743-53.

16. Gerber LH, Stout N, McGarvey C, Soballe P, Shieh CY, Diao G, et al. Factors predicting clinically significant fatigue in women following treatment for primary breast cancer. Support Care Cancer. 2011;19(10):1581-91.

17. Goldstein D, Bennett BK, Webber K, Boyle F, de Souza PL, Wilcken NR, et al. Cancer-related fatigue in women with breast cancer: outcomes of a 5-year prospective cohort study. J Clin Oncol. 2012;30(15):1805-12.

18. Pertl MM, Hevey D, Collier S, Lambe K, O'Dwyer AM. Predictors of fatigue in cancer patients before and after chemotherapy. J Health Psychol. 2014;19(6):699-710.

19. Altice CK, Banegas MP, Tucker-Seeley RD, Yabroff KR. Financial hardships experienced by cancer survivors: a systematic review. J Natl Cancer Inst. 2017;109(2):djw205.

20. Azzani M, Roslani AC, Su TT. The perceived cancer-related financial hardship among patients and their families: a systematic review. Support Care Cancer. 2015;23(3):889-98.

21. Bradley CJ. Financial hardship: a consequence of survivorship? J Clin Oncol. 2012;30(14):1579-80.

22. Gordon LG, Merollini KMD, Lowe A, Chan RJ. A systematic review of financial toxicity among cancer survivors: we can't pay the co-pay. Patient. 2017;10(3):295-309.

23. Lu L, O'Sullivan E, Sharp L. Cancer-related financial hardship among head and neck cancer survivors: risk factors and associations with health-related quality of life. Psychooncology. 2019;28(4):863-71.

24. Benoit FR. Cumulative financial stress and strain in palliative radiation outpatients: the role of age and disability. Acta Oncol. 2005;44(4):369-81.

25. Banegas MP, Guy GP Jr, de Moor JS, Ekwueme DU, Virgo KS, Kent EE, et al. For working-age cancer survivors, medical debt and bankruptcy create financial hardships. Health Aff (Millwood). 2016;35(1):54-61.

26. Zafar SY, McNeil RB, Thomas CM, Lathan CS, Ayanian JZ, Provenzale D. Population-based assessment of cancer survivors' financial burden and quality of life: a prospective cohort study. J Oncol Pract. 2014;11(2):145-50.

27. Shankaran V, Jolly S, Blough D, Ramsey SD. Risk factors for financial hardship in patients receiving adjuvant chemotherapy for colon cancer: a population-based exploratory analysis. J Clin Oncol. 2012;30(14):1608-14.

28. Sharp L, Carsin AE, Timmons A. Associations between cancerrelated financial stress and strain and psychological well-being among individuals living with cancer. Psychooncology. 2013;22(4):745-55.

29. Ell K, Xie B, Wells A, Nedjat-Haiem F, Lee PJ, Vourlekis B. Economic stress among low-income women with cancer: effects on quality of life. Cancer. 2008;112(3):616-25.

30. Fenn KM, Evans SB, McCorkle R, DiGiovanna MP, Pusztai L, Sanft T, et al. Impact of financial burden of cancer on survivors' quality of life. J Oncol Pract. 2014;10(5):332-8.

31. Shao Z, Zhu T, Zhang P, Wen Q, Li D, Wang S. Association of financial status and the quality of life in Chinese women with recurrent ovarian cancer. Health Qual Life Outcomes. 2017;15(1): 144.

32. Chan RJ, Gordon L, Zafar SY, Miaskowski C. Financial toxicity and symptom burden: what is the big deal? Support Care Cancer. 2018;26(5):1357-9.

33. Drummond FJ, Kinnear H, Donnelly C, O'Leary E, O'Brien K, Burns RM, et al. Establishing a population-based patient-reported outcomes study (PROMs) using national cancer registries across two jurisdictions: the Prostate Cancer Treatment, your experience (PiCTure) study. BMJ Open. 2015;5(4):e006851.

34. Aaronson NK, Ahmedzai S, Bergman B, Bullinger M, Cull A, Duez NJ, et al. The European Organization for Research and Treatment of Cancer QLQ-C30: a quality-of-life instrument for use in international clinical trials in oncology. J Natl Cancer Inst. 1993;85(5):365-76.

35. Groenvold M, Klee MC, Sprangers MAG, Aaronson NK. Validation of the EORTC QLQ-C30 quality of life questionnaire through combined qualitative and quantitative assessment of patient-observer agreement. J Clin Epidemiol. 1997;50(4):441-50. 
36. Giesinger JM, Kuijpers W, Young T, Tomaszewski KA, Friend E, Zabernigg A, et al. Thresholds for clinical importance for four key domains of the EORTC QLQ-C30: physical functioning, emotional functioning, fatigue and pain. Health Qual Life Outcomes. 2016;14: 87.

37. Sharp L, O'Leary E, O'Ceilleachair A, Skally M, Hanly P. Financial impact of colorectal cancer and its consequences: associations between cancer-related financial stress and strain and healthrelated quality of life. Dis Colon Rectum. 2018;61(1):27-35.

38. Hosmer DW, Lemeshow S, Klar J. Goodness-of-fit testing for the logistic-regression model when the estimated probabilities are small. Biom J. 1988;30(8):911-24.

39. Chan RJ, Gordon LG, Tan CJ, Chan A, Bradford NK, Yates P, et al. Relationships between financial toxicity and symptom burden in cancer survivors: a systematic review. J Pain Symptom Manag. 2019;57(3):646-60.

40. Housser E, Mathews M, Lemessurier J, Young S, Hawboldt J, West R. Responses by breast and prostate cancer patients to out-of-pocket costs in Newfoundland and Labrador. Curr Oncol. 2013;20(3):15865 .

41. Sharp L, Timmons A. Pre-diagnosis employment status and financial circumstances predict cancer-related financial stress and strain among breast and prostate cancer survivors. Support Care Cancer. 2016;24(2):699-709.

42. Cancer Research UK. Deprivation gradient for cancer incidence. Available at: https://www.cancerresearchukorg/healthprofessional/cancer-statistics/incidence/deprivation-gradient\# heading-One. Accessed 12/11/2019.

43. Delgado-Guay M, Ferrer J, Rieber AG, Rhondali W, Tayjasanant S, Ochoa J, et al. Financial distress and its associations with physical and emotional symptoms and quality of life among advanced cancer patients. Oncologist. 2015;20(9):1092-8.

44. Lathan CS, Cronin A, Tucker-Seeley R, Zafar SY, Ayanian JZ, Schrag D. Association of financial strain with symptom burden and quality of life for patients with lung or colorectal cancer. $\mathrm{J}$ Clin Oncol. 2016;34(15):1732-40.

45. Barbaret C, Brosse C, Rhondali W, Ruer M, Monsarrat L, Michaud $\mathrm{P}$, et al. Financial distress in patients with advanced cancer. PLOS ONE 2017;12(5):e0176470.

46. Charalambous A, Kouta C. Cancer related fatigue and quality of life in patients with advanced prostate cancer undergoing chemotherapy. Biomed Res Int. 2016;2016:3989286.

47. Luo HC, Lei Y, Cheng HH, Fu ZC, Liao SG, Feng J, et al. Longterm cancer-related fatigue outcomes in patients with locally advanced prostate cancer after intensity-modulated radiotherapy combined with hormonal therapy. Medicine (Baltimore). 2016;95(25): e3948.

48. Mehnert A. Employment and work-related issues in cancer survivors. Crit Rev Oncol Hematol. 2011;77(2):109-30.

49. Islam T, Dahlui M, Majid HA, Nahar AM, Mohd Taib NA, Su TT, et al. Factors associated with return to work of breast cancer survivors: a systematic review. BMC Public Health. 2014;14 Suppl 3: S8.

50. Wolvers MDJ, Leensen MCJ, Groeneveld IF, Frings-Dresen MHW, De Boer A. Predictors for earlier return to work of cancer patients. J Cancer Surviv. 2018;12(2):169-77.

51. Bennett D, Kearney T, Donnelly DW, Downing A, Wright P, Wilding $\mathrm{S}$, et al. Factors influencing job loss and early retirement in working men with prostate cancerfindings from the populationbased Life After Prostate Cancer Diagnosis (LAPCD) study. J Cancer Surviv. 2018;12(5):669-78.

52. Torp S, Paraponaris A, Van Hoof E, Lindbohm ML, Tamminga SJ, Alleaume C, et al. Work-related outcomes in self-employed cancer survivors: a European multi-country study. J Occup Rehabil. 2019;29(2):361-74.
53. Sharp L, Timmons A. Financial impact of a cancer diagnosis. National Cancer Registry/Irish Cancer Society, Cork/Dublin. 2010. Available at: http://www.ncri.ie/sites/ncri/files/pubs/ FinancialImpactofaCancerDiagnosis(FullReport).pdf. Accessed $13 / 11 / 2019$.

54. Mustian KM, Alfano CM, Heckler C, Kleckner AS, Kleckner IR, Leach CR, et al. Comparison of pharmaceutical, psychological, and exercise treatments for cancer-related fatigue: a meta-analysis. JAMA Oncol. 2017;3(7):961-8.

55. National Comprehensive Cancer Network. Clinical practice guidelines in oncology. Cancer-related fatigue. Version 2.2020. Available at: https://www.nccn.org/professionals/physician_gls/ pdf/fatigue.pdf. Accessed 31/05/2020.

56. Mayer A, Foster M. Understanding recession and self-rated health with the partial proportional odds model: an analysis of 26 countries. PLoS One. 2015;10(10):e0140724.

57. Marshall GL, Tucker-Seeley R. The association between hardship and self-rated health: does the choice of indicator matter? Ann Epidemiol. 2018;28(7):462-7.

58. Engberg I, Segerstedt J, Waller G, Wennberg P, Eliasson M. Fatigue in the general population- associations to age, sex, socioeconomic status, physical activity, sitting time and self-rated health: the northern Sweden MONICA study 2014. BMC Public Health. 2017;17(1):654.

59. Kohler N, Gansera L, Holze S, Friedrich M, Rebmann U, Stolzenburg JU, et al. Cancer-related fatigue in patients before and after radical prostatectomy. Results of a prospective multicentre study. Support Care Cancer. 2014;22(11):2883-9.

60. O'Ceilleachair A, Costello L, Finn C, Timmons A, Fitzpatrick P, Kapur K, et al. Inter-relationships between the economic and emotional consequences of colorectal cancer for patients and their families: a qualitative study. BMC Gastroenterol. 2012;12:62.

61. Meeker CR, Geynisman DM, Egleston BL, Hall MJ, Mechanic $\mathrm{KY}$, Bilusic M, et al. Relationships among financial distress, emotional distress, and overall distress in insured patients with cancer. $\mathrm{J}$ Oncol Pract. 2016;12(7):e755-64.

62. Saligan LN, Kim HS. A systematic review of the association between immunogenomic markers and cancer-related fatigue. Brain Behav Immun. 2012;26(6):830-48.

63. Bower JE. Cancer-related fatigue-mechanisms, risk factors, and treatments. Nat Rev Clin Oncol. 2014;11(10):597-609.

64. Thong MSY, Mols F, van de Poll-Franse LV, Sprangers MAG, van der Rijt CCD, Barsevick AM, et al. Identifying the subtypes of cancer-related fatigue: results from the population-based PROFILES registry. J Cancer Surviv. 2018;12(1):38-46.

65. Colloca G, Venturino A, Governato I, Checcaglini F. Incidence and correlates of fatigue in metastatic castration-resistant prostate cancer: a systematic review. Clin Genitourin Cancer. 2016;14(1):5-11.

66. Irvine D, Vincent L, Graydon JE, Bubela N, Thompson L. The prevalence and correlates of fatigue in patients receiving treatment with chemotherapy and radiotherapy. A comparison with the fatigue experienced by healthy individuals. Cancer Nurs. 1994;17(5):367-78.

67. Tabrizi FM, Alizadeh S. Cancer related fatigue in breast cancer survivors: in correlation to demographic factors. Maedica (Buchar). 2017;12(2):106-11.

68. Deimling GT, Bowman KF, Wagner LJ. The effects of cancerrelated pain and fatigue on functioning of older adult, Long-Term Cancer Survivors. Cancer Nurs. 2007;30(6):421-33.

69. Friedrich M, Nowe E, Hofmeister D, Kuhnt S, Leuteritz K, Sender A, et al. Psychometric properties of the fatigue questionnaire EORTC QLQ-FA12 and proposal of a cut-off value for young adults with cancer. Health Qual Life Outcomes. 2018;16:125.

70. Mendoza T, Wang XS, Cleeland CS, et al. The rapid assessment of fatigue severity in cancer patients: use of the Brief Fatigue Inventory. Cancer. 1999;85:1186-96. 
71. Khera N, Holland JC, Griffin JM. Setting the stage for universal financial distress screening in routine cancer care. Cancer. 2017;123(21):4092-6.

72. de Souza JA, Yap BJ, Wroblewski K, Blinder V, Araujo FS, Hlubocky FJ, et al. Measuring financial toxicity as a clinically relevant patient-reported outcome: the validation of the COmprehensive Score for financial Toxicity (COST). Cancer. 2017;123(3):476-84.

73. Macmillan Cancer Support. Benefits and other financial support. 2019. Available at: http://www.macmillan.org.uk/informationand-support/organising/benefits-and-financial-support. Accessed $13 / 11 / 2019$.

74. Moffatt S, Noble E, Exley C. "Done more for me in a fortnight than anybody done in all me life." How welfare rights advice can help people with cancer. BMC Health Serv Res. 2010;10:259.
75. Cancer Council Australia. Practical and financial assistance. Available at: https://www.cancer.org.au/about-cancer/patientsupport/practical-and-financial-assistance.html. Accessed 31/05/ 2020.

76. Irish Cancer Society. Travel2Care. Available at : https://www. cancer.ie/cancer-information-and-support/cancer-support/gettingorganised/organising-travel/travel2care. Accessed 31/05/2020.

77. Macmillan Cancer Support. Employers. Available : https://www. macmillan.org.uk/cancer-information-and-support/get-help/helpwith-work/employers. Accessed 31/05/2020.

Publisher's note Springer Nature remains neutral with regard to jurisdictional claims in published maps and institutional affiliations. 